\title{
Don't just do something, stand there
}

\author{
Não se limite a fazer algo, esteja lá
}

\section{No se limite a hacer algo, esté allí}

Jerome R Hoffman, MA MD. Professor Emeritus of Medicine. UCLA School of Medicine. Los Angeles, USA. jrh@ucla.edu (Corresponding author) Michael S Wilkes, MD PhD. Professor of Medicine and Global Health. UC Davis School of Medicine. Sacramento, USA. mwilkes@ucdavis.edu

Imagine a (hypothetical) screening test which, done in a population of average risk, saves one person from dying from cancer out of every 10,000 people screened. Imagine as well that every one of those 10,000 pays a price in terms of time and money spent, as well as discomfort, and that some or even many of them will also have to deal with increased anxiety, repeat testing, biopsies, and in a few cases, surgery. Finally, a few will have serious adverse effects like infection or organ failure.

Presented with this information, some people would undoubtedly decline to have the test ("You mean only one out of 10,000 who get the test will benefit?!"), while others would choose to have it ("I'll put up with all that if it could save my life"). That is to say, informed patients would understand that they are making a choice between a very rare but very important benefit, that would however accrue to almost none of the people getting the test, and very frequent, but far more manageable, harms, that would have to be dealt with by almost everyone getting the test.

Now imagine a patient with osteoarthritis offered treatment with a (hypothetical) non-steroidal anti-inflammatory drug (NSAID), where the doctor notes that most patients would get a fairly small degree of benefit (more pain relief than with an analgesic with fewer side effects), but that perhaps one in 10,000 would suffer terrible harm (from GI bleeding, or renal failure). In this case, an informed patient would understand that this is a choice between a very small benefit that would apply to many people, and a terrible harm that would nevertheless be very rare.

The two situations are comparable, such that it would make sense that after a shared decision-making discussion with an informed physician, almost all informed patients would choose both to forgo the screening test and to take the NSAID, or to do just the opposite in both instances. The first combination should be the choice of individuals who are not terribly concerned about extremely rare events, no matter how important they might be, and are more interested in very common effects (harms in the case of screening, and benefits in the case of the NSAID), even if they are relatively less important. The opposite choice would be made by those who are greatly concerned about a critical problem (a hidden disease that a screening test might detect, or a terrible drug side effect), no matter how rare. There could be occasional exceptions to this pattern, but one would expect the large majority of people to make similar choices consistent with the same set of underlying values and preferences.

So how is it that in today's world most patients - and most of their doctors - automatically choose both a series of screening tests that have an extremely high number-needed-to-screen for one person to benefit, and drugs that offer only a very small additive benefit while occasionally producing lifethreatening harm? (One could argue, in fact, that the two scenarios presented are both overly optimistic, since few if any screening tests actually affect overall, rather than disease-specific, mortality, and because there are very few conditions where an NSAID actually provides any advantage over acetaminophen.)

\author{
Funding: \\ none declared. \\ Ethical approval: \\ not applicable. \\ Competing interests: \\ none declared. \\ Provenance and peer review: \\ commissioned by the editors, \\ not externally reviewed. \\ Received: 12/10/2014 \\ Accepted: 14/12/2014
}


Physicians are taught, right from the start of medical school, that medical care is a powerful weapon to be used in fighting disease. This is of course in some ways true. They are also taught that harm can occur with all sorts of individual treatments. But this is typically little more than an afterthought; medical thinking generally precedes along the lines of "what shall we do (as safely as possible, of course"), rather than "should we do something?" That is to say, while we acknowledge the possibility of harm, we viscerally believe - and have taught patients also to believe - that doing something should be the default choice whenever a patient is sick ... and often even before they are actually sick.

We rely on concepts of "disease" that are in fact only risk factors, and find reassurance in "successful" treatment of surrogate markers, even when (as is the rule, rather than the exception) such success is unassociated with any change in patient-oriented outcomes. We have internalized - and again, led patients to believe almost as a matter of faith - a number of truly dangerous myths about healthcare, such as "earlier is better" (and more is always better), "technology will solve all our problems," "miracles are right around the corner," "once we identify genetic risk factors there will be a perfect tailored treatment for each of us," and ultimately - if we're only clever enough ... and spend enough - death will soon be optional.

Quaternary prevention, or P4, offers a new paradigm, by insisting that medical harm is far from a trivial, or secondary, concern. It tells us that preventing harm from medical interventions - which has been proven to be a major cause of death and disability in "advanced" societies - deserves equal consideration as does preventing harm from disease.

This is different than the commonly cited "first do no harm," which is commonly misunderstood to mean "don't do anything that could cause harm." Quaternary Prevention, on the other hand, acknowledges the critical fact that everything we do in health care can cause harm - so refusing to do anything that isn't perfectly safe would mean never doing anything! That would be a terrible mistake, as medicine does indeed have a great deal to offer. But in helping patients make decisions we, and they, must consider the potential for harm every bit as prominently as we consider the potential for benefit.

Furthermore, by asking, "should we do something," we don't actually mean "do nothing." We can always offer support, and comfort, and symptomatic care - for all of which the number needed to treat to benefit one patient ... approaches one. (Compare that to most chronic disease treatments, where the NNT is at least $100 \ldots$ which means that with such "treatment" the likelihood that any given individual will benefit is in fact remote.)

Acknowledging this in our heads is only a tiny first step; if we want to reverse a milieu where "medicine's much hailed ability to help the sick is fast being challenged by its propensity to harm the healthy," ${ }^{1}$ we must incorporate, into the very DNA of medical education, and practice, P4's simple and obvious, but also revolutionary, admonishment - that doing what we can to prevent medical harm must become one of the pillars of modern healthcare. Only when we viscerally incorporate this into our practice will we become worthy contributors to truly rational shared decision-making with our patients.

\section{References}

1. Moynihan R, Doust J, Henry D. Preventing overdiagnosis: how to stop harming the healthy. BMJ. 2012 May 28;344:e3502. 